\title{
LETTERS
}

\section{A priority-setting framework is needed to understand the value of investing in a universal drug plan}

The exclusion of community-prescribed medication from Canada's package of universal health care is an anomaly that deserves the attention it has received over the past 25 years and more. The reliance on direct payments in the form of out-of-pocket costs poses a substantial barrier to accessing effective drugs in Canada, and this quite likely poses substantial downstream economic pressures on the health system.

Universal public financing of an essential list of medicines, as proposed by Morgan and colleagues in their article in CMAJ, ${ }^{1}$ means that, in addition to current public (and private) drug plan funding for other drugs, the government will finance the selected drugs irrespective of who is providing or receiving them, and if truly universal, this financing mechanism will increase coverage in vulnerable population groups. We offer two additional points to this policy debate.

First, the extent of shifts in costs from patients and private drug plans to government relies on Canada moving toward a quasi-monopsony market, driving down generic prices but also substantially shifting prescribing and utilization patterns to the agents on the essential medicines list from (higher-cost) alternatives within pharmacologic and therapeutic classes. Argu- ably, economic and financial incentives for this shift already exist in the market given that lower-cost alternatives are available. The estimated costs, therefore, rely on public financing providing additional incentives to prescribers and patients, but also sufficiently overcoming nonfinancial barriers that presently prohibit the prescribing of generic, low-cost alternatives. In short, incentives must be aligned.

Second, although the size of the estimated incremental cost to government appears modest overall, funds will need to be raised through taxation or will need to be released from somewhere else in the system. By funding these particular agents, there is an implicit prioritization of the drugs on the list over all other potential candidates. Under a value-formoney framework, this means that the specific drugs, when compared with others, will give greater benefits for the additional cost.

Although this may be the case, to ensure that the proposed investment provides sufficient social value to the health system, it is imperative that decisions about implementing universal public financing, either in part or in full, are considered within a robust framework for priority setting and resource allocation. ${ }^{2}$ Within this framework, the explicit budget that would be required to implement effectively a universal drug plan should be considered alongside the opportunity costs elsewhere in the health care system.
The move toward true universal access should be welcomed, and government should certainly move in the direction proposed by Morgan and colleagues. ${ }^{1}$ In so doing, close attention must be paid to the impact of public finance on the dimensions of equity, fairness and financial risk protection, in addition to health maximization.

\section{Tracey-Lea Laba BPharm PhD}

Research Fellow, Centre for Clinical Epidemiology and Evaluation, and School of Population and Public Health, The University of British Columbia, Vancouver, BC; Menzies Centre for Health Policy, University of Sydney, Sydney, Australia

\section{Craig Mitton MSc PhD}

Professor, Centre for Clinical Epidemiology and Evaluation, and School of Population and Public Health, The University of British Columbia, Vancouver, BC

Cite as: CMAJ 2017 May 15;189:E704. doi: $10.1503 / \mathrm{cmaj} .732990$

\section{References}

1. Morgan SG, Li W, Yau B, et al. Estimated effects of adding universal public coverage of an essential medicines list to existing public drug plans in Canada. CMAJ 2017;189:E295-302.

2. Smith N, Mitton C, Hall W, et al. High performance in healthcare priority setting and resource allocation: a literature- and case studybased framework in the Canadian context. Soc Sci Med 2016;162:185-92.

Competing interests: None declared. 